\title{
Efetividade na restauração de florestas tropicais: como o desempenho diferencial das espécies e o contexto ecológico influenciam o estabelecimento e ocupação
}

\author{
Juliano de Paulo dos SANTOS ${ }^{*}$, Cléber Rodrigo de SOUZA², Michele Aparecida Pereira da SILVA², \\ Joelma de Paulo SILVA², Soraya Alvarenga BOTELHO²
}

${ }^{1}$ Instituto de Ciências Agrárias e Ambientais, Universidade Federal de Mato Grosso, Sinop, MT, Brasil. ${ }^{2}$ Departamento de Ciências Florestais, Universidade Federal de Lavras, Lavras, MG, Brasil.

*E-mail: juliano_engflorestal@yahoo.com.br

(ORCID: 0000-0001-8347-0240; 0000-0002-4122-2748; 0000-0001-8387-961X; 0000-0003-0988-4861; 0000-0003-4178-465X)

Recebido em 05/02/2021; Aceito em 11/10/2021; Publicado em 19/10/2021.

\begin{abstract}
RESUMO: Restaurar as florestas tropicais é essencial para enfrentar mudanças climáticas globais, manter e conservar a diversidade e os serviços ecossistêmicos. Foi analisado o estabelecimento e ocupação em três estratégias de restauração florestal (Plantio em Mudas em Área Total (PAT), Ilhas de Diversidade (ID) e Semeadura Direta (SD)) da vegetação florestal associada a cursos d'água. Foram avaliados: o número de indivíduos, intensidade de perfilhamento, biomassa acima do solo, área de copa, diâmetro e altura médios, por indivíduo, em 58 unidades amostrais $(10 \times 30 \mathrm{~m})$ distribuídas entre as estratégias após 2,5 anos da implantação. Também foram avaliadas as principais espécies e suas similaridades entre as estratégias. A SD proporcionou maior efetividade quanto ao Número de indivíduos, Biomassa e Área de Copa, enquanto, a intensidade de perfilhamento foi maior nas ID e não houveram diferenças quanto a média de altura e diâmetro. Cada estratégia apresentou um conjunto particular de espécies de maior sucesso e as mais similares foram aquelas que utilizaram mudas (PAT e ID). A estratégia SD destacou-se no estudo, especialmente quando considerados aspectos ecológicos e custos envolvidos. As espécies contribuíram na diferenciação das estratégias, pois, proporcionaram funções ecológicas distintas que influenciam processos ecológicos em nível de comunidade e indivíduos.

Palavras-chave: restauração florestal; nucleação; semeadura direta; plantio de mudas; floresta Amazônica.
\end{abstract}

\section{Effectiveness in the tropical forest restoration: how the differential performance of species and ecological context affect the establishment and occupation}

\begin{abstract}
Restoring tropical forests is essential to address global climate change, to maintain and conserve diversity and ecosystem services. The establishment and occupation of three forest restoration strategies (Total Seedling Planting (PAT), Diversity Islands (ID) and Direct Seeding (SD)) of the forest vegetation associated with watercourses was analyzed. It were evaluated: the number of individuals, resprouting intensity, aboveground biomass, canopy area, average diameter and height, per individual, in 58 sample units $(10 \times 30 \mathrm{~m})$ distributed among the strategies after 2.5 years of implantation. It was also evaluated the main species and their similarities between the strategies. The SD provided more effective as the number of individuals, biomass and treetop area, while the intensity of resprouting was higher in ID and there were no differences in mean height and diameter. Each strategy presented a particular set of most successful species and the most similar were those that used seedlings (PAT and ID). The highlight of the SD strategy is magnified when considering ecological perspectives, and social costs involved. The species contributed to the differentiation of strategies, because they provide distinct ecological functions that influence ecological processes at the community level and individuals.
\end{abstract}

Keywords: forest restoration; nucleation; direct seeding; seedling planting; Amazon rainforest.

\section{INTRODUÇÃO}

As florestas tropicais abrigam grande parte da biodiversidade global e sua manutenção está diretamente associada a diversos processos essenciais para o funcionamento dos ecossistemas e para a humanidade (CHAZDON; ARROYO, 2013; ISBELL et al., 2017; ISBELL et al., 2018; WATSON et al., 2018). Em geral, tais serviços ecossistêmicos diretamente associados a biodiversidade estão associados a provisão de recursos alimentares, estruturais e genéticos, controle do clima e mitigação de consequências negativas oriundas de atividades antrópicas, tais como a absorção de carbono oriundo de combustíveis fosseis (HOUGHTON et al., 2015; ISBELL et al., 2017; MORI et al., 2017; MITCHARD, 2018; SPRACKLEN et al., 2018).

O cenário de degradação no mundo foi revisado por Gibbs; Salmon, (2015) e as estimativas globais indicam que o total de áreas degradadas é de menos de 1 bilhão de hectare a mais de 6 bilhões de hectares com ampla discordância em sua distribuição espacial. Para as florestas tropicais esta estimativa pode chegar a 500 milhões de ha, podendo, assim, 
afetar a subsistência de milhões de pessoas, especialmente aquelas alocadas nos trópicos (ASNER et al., 2009). Os impactos negativos da degradação comprometem o funcionamento e serviços ambientais provisionados pelos ecossistemas florestais, pois, alteram os padrões de dinâmica e desempenho funcional desses ambientes (CARDINALE et al., 2012; GHAZOUL; CHAZDON, 2017). Neste sentido, soluções para mitigar estes problemas de degradação devem ser abordadas do ponto de vista viável, deixando de lado o idealismo. Assim, o desenvolvimento de novas políticas de conservação deve ser priorizado e baseado em esforços para restaurar áreas florestais degradadas e criar áreas protegidas para garantir, assim, os benefícios em longo prazo para toda a humanidade (GHAZOUL; CHAZDON, 2017; WATSON et al., 2017).

Atualmente, governos de todo o mundo, bem como empresas e tomadores de decisão têm procurado promover iniciativas globais de restauração florestal, como o "Bonn Challenge", lançado em 2011 com o compromisso de restaurar 150 milhões de hectares até 2020 (Bonn Challenger, 2019); a Declaração de Nova York (ONU, 2019), propondo a restauração de outros 200 milhões de hectares; e a Iniciativa 20 x 20 lançada em 2014 pelos países da América Latina para restaurar 20 milhões de hectares até 2020 (WRI, 2019).

Restaurar ecossistemas florestais tropicais é um dos principais desafios globais, sendo ainda necessário gerar informações sobre as atividades a serem implementadas, buscar práticas efetivas com diferentes estratégias a serem utilizadas dependendo das situações encontradas in situ, além de selecionar espécies mais funcionalmente apropriadas para serem utilizadas em cada caso específico (GUARIGUATA; BRANCALION, 2014; BRANCALION; Van MELIS, 2017). A decisão a ser tomada em relação à área a ser restaurada é o primeiro passo para recuperar áreas degradadas em seus aspectos físicos, químicos e biológicos e por consequência restaurar sua capacidade produtiva (HOLL, 2013; PERRING et al., 2015; BRANCALION; Van MELIS, 2017).

A vegetação nativa próxima a córregos é reconhecida como importante para as sociedades em todo o mundo. $\mathrm{Na}$ zona ribeirinha, além do abrigo da biodiversidade com a prestação de serviços ambientais, os solos úmidos e sua vegetação nas zonas de influência dos rios e lagos são ecossistemas de reconhecida importância na mitigação de inundações e vazantes, na redução da erosão superficial, no condicionamento da qualidade da água e na manutenção dos canais, pela proteção dos córregos e pela redução do assoreamento (TABACCHI et al., 2000; DOSSKEY et al., 2010). Existe um amplo consenso científico de que em função de sua importância na estabilidade e funcionalidade, estes ecossistemas precisam ser preservados ou restaurados, se degradados (DOSSKEY et al., 2010; SILVA et al., 2012).

Nesse contexto, estudos que elucidam a base científica do processo de restauração ecológica das florestas tropicais são essenciais, pois, nos permitirão superar os desafios e projetar a escala necessária para torná-la uma medida inteligente de conservação da diversidade e enfrentar as mudanças climáticas globais. Esse avanço permitirá o desenho de projetos robustos e dinâmicos que possam reverter $\mathrm{O}$ processo de degradação sob aspectos funcionais e estruturais, a medida que concomitantemente permite a regulação e a manutenção dos serviços ambientais esperados com a atividade (BRANCALION et al., 2013; DURIGAN; ENGEL, 2012). Considerando esta necessidade de construção de conhecimento a respeito de medidas de potencialização do sucesso da restauração em florestas tropicais, nosso objetivo foi comparar a eficácia de três estratégias de restauração florestal em áreas degradadas 2,5 anos após implantação em florestas amazônicas em Áreas de Preservação Permanente. Nós avaliamos esta efetividade em diferentes aspectos da vegetação arbórea, analisando variáveis associadas ao estabelecimento, sucesso individual e proteção do solo.

\section{MATERIAL E MÉTODOS}

\section{1. Áreas de estudo}

A área de estudo está localizada na Fazenda São Nicolau (FSN), no município de Cotriguaçu, na porção noroeste do Mato Grosso - Brasil. (-9.859354ㅇ ; $58.250445^{\circ}$ ) (Figura 1). A fazenda está localizada na margem esquerda do rio Juruena, que junto com o rio Teles Pires forma o rio Tapajós, um dos maiores rios da Amazônia (SILVEIRA et al., 2017). O clima da região é tropical quente e úmido (Aw na classificação de Koppen), com temperatura média de $24^{\circ} \mathrm{C}$ e umidade relativa em torno de $80 \%$ (VOURLITIS et al., 2002; SOUZA et al., 2013). A precipitação média anual é de $2034 \mathrm{~mm}$, com a estação chuvosa de outubro a março, e a estação seca no inverno, de abril a setembro (NORONHA et al., 2015). O relevo na região é plano e a altitude média é de 297 m. A região está inserida no domínio fitogeográfico Amazônico, em proximidade com o limite sudeste com o domínio dos Cerrados, com a paisagem sendo marcada por Florestas de Terra baixa e florestas aluviais nas áreas próximas a cursos d'água (BRASIL, 2012).

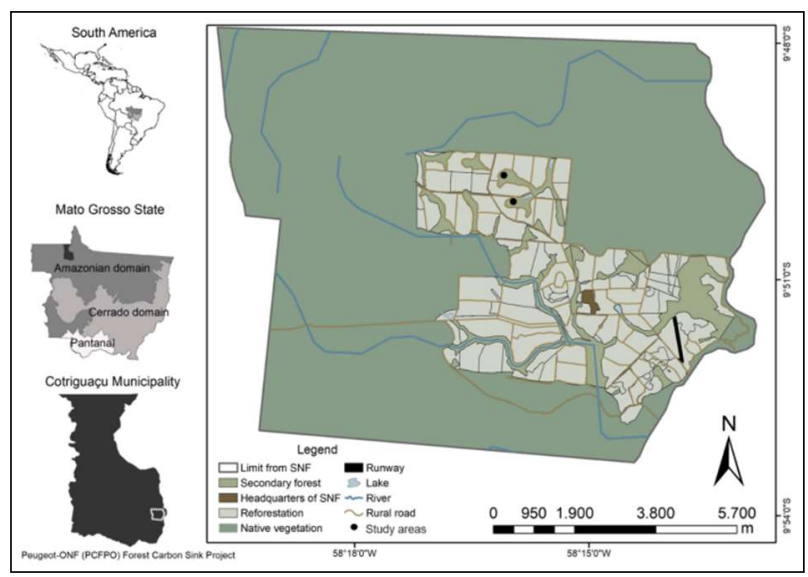

Figura 1. Localização das áreas de estudo, na borda sul da Amazônia. Figure 1. Location of study areas, on the southern edge of the Amazon.

A Fazenda São Nicolau consiste em um projeto de Poço de Carbono implantando em 1998 pela empresa construtora de automóveis francesa Peugeot, em parceria com a empresa de gestão florestal ONF-Brasil (Ofice National des Fôrets). O projeto foi implantado com o objetivo de sequestrar e estocar carbono atmosférico através do plantio e crescimento de árvores na recuperação de áreas degradadas da propriedade. Em 2000 quando foi realizado o licenciamento ambiental foram detectados 455,84 ha de Áreas de Preservação Permanentes Degradadas (APPD), valor que diminuiu para 166,31 ha com as iniciativas do Projeto de Reflorestamento Poço de Carbono Peugeot - ONF e que está atualmente em cerca de 123,94 ha. Esta iniciativa foi firmada juntamente ao órgão ambiental responsável na região 
(Secretaria de Estado do Meio Ambiente do Mato Grosso SEMA), com o compromisso de restauração anual de 12 ha previamente utilizados como área de pastagem. Na fazenda o principal fator de degradação foi a derrubada da floresta nativa para a exploração madeireira e estabelecimento de pastagens, seguido pela compactação do solo causada pela atividade pecuária realizada na área (SILVEIRA et al., 2017).

\subsection{Seleção de espécies e implantação das estratégias de restauração}

O primeiro passo do processo de restauração foi o isolamento da área, que é necessária para evitar a pastagem de gado no local e de outros fatores de degradação que possam afetar o desenvolvimento da restauração.

A preferência na seleção foi dada às espécies nativas das fisionomias florestais da região, especialmente aquelas associadas aos cursos de água. Para isso, inicialmente consultamos as espécies implantadas no Projeto Preenchimento de Carbono Florestal Peugeot-ONF (PCFPO) e espécies já conhecidas por serem atraentes para a vida selvagem em áreas ribeirinhas da fazenda (Silveira et al., 2017), bem como, observamos in loco as espécies que se regeneravam com abundancia nas áreas ciliares da Fazenda São Nicolau. Também avaliamos aspectos funcionais das espécies como o fornecimento de recurso e atração da fauna, grupo ecológico na sucessão florestal, informação sobre o ritmo de crescimento da espécie, adaptabilidade a áreas úmidas, entre outras características importantes para o estabelecimento e sucesso das espécies. Após análise criteriosa da identificação das informações ecológicas e silviculturais disponíveis e da ocorrência nas matas ciliares da região foram pré-selecionadas 59 espécies (Tabela 1). A produção de mudas foi realizada na própria fazenda, com sementes oriundas de coletores de sementes da região e de coletas realizadas pelos integrantes da equipe na própria fazenda. Para a realização do preparo da área foi utilizado a roçagem mecânica e adubação em área total.

Tabela 1. Espécies utilizadas nas estratégias de implantação na Fazenda São Nicolau, Amazônia, Brasil. Os nomes populares correspondem a forma em língua portuguesa da nomeação utilizada na região.

Table 1. Species used in the implantation strategies at Fazenda São Nicolau, Amazônia, Brazil. The popular names correspond to the Portuguese language form of the nomination used in the region.

\begin{tabular}{l}
\hline Família/Espécie \\
\hline ANACARDIACEAE \\
Anacardium giganteum W. Hancock ex Engl \\
Anacardium bumile A. St. - Hill \\
Anacardium occidentale L. \\
Astronium lecointei Ducke \\
Myracrodruon urundeuva Allemão \\
Spondias mombin L. \\
ANONACEAE \\
Xilopia sp. \\
APOCYNACEAE \\
Aspidosperma subincanum Mart. \\
Rauvolfia paraenses Ducke \\
ARECACEAE \\
Euterpe oleracea Mart. \\
BIGNONIACEAE \\
Handroanthus impetiginosus (Mart. ex DC.) Mattos \\
Handroanthus serratifolius (A.H.Gentry) S. Grose \\
Tabebuia sp. \\
BIXACEAE \\
Bixa orellana L. \\
CANNABACEAE \\
Trema micrantha (L.) Blume \\
CARYOCARECAE \\
Caryocar glabrum(Aubl.) Pers. \\
CHRYSOBALANACEAE
\end{tabular}
Nome popular

Cajueiro

Caju

Caju

Muiracatiara

Aroeira

Cajá

Pindaíba

peroba mica peroba da água

Açai

ipê-rosa

ipê-amarelo

Ipê

Colorau

Piriquiteira

Pequi

guariuba/orticica

\begin{tabular}{|c|c|}
\hline Família/Espécie & Nome popular \\
\hline \multicolumn{2}{|l|}{ DICHAPETALACEAE } \\
\hline Tapura amazônica Poepp. \&Endl. & Espeteiro \\
\hline \multicolumn{2}{|l|}{ EUPHORBIACEAE } \\
\hline Hevea brasiliensis (Willd. ex A.Juss.) Müll.Arg. & Mamoninha \\
\hline Mabea fistulifera Mart. & Seringueira \\
\hline \multicolumn{2}{|l|}{ FABACEAE } \\
\hline Amburana cearensis (Fr. All.) A. C. Smith & Cerejeira \\
\hline Anadenanthera colubrina (Vell.) Brenan & angelim doce \\
\hline Anadenanthera sp 1 & Angiquinho \\
\hline Anadenanthera sp 2 & angico-amarelo \\
\hline Andira legalis (Vell.) Toledo & angico vermelho \\
\hline Baubinia acreana Harms & pata de vaca \\
\hline Cajanus cajan (L.) Huth & feijão cru \\
\hline Copaifera langsdorffii Desf. & Copaíba \\
\hline Dipteryx odorata (Aubl.) Willd. & Cumaru \\
\hline Enterolobium contortisiliquum (Vell.) Morong & Orelinha \\
\hline Enterolobium schomburgkii (Benth.) Benth. & Timburi \\
\hline \multicolumn{2}{|l|}{ Erythrina sp. } \\
\hline Hymenaea courbaril $\mathrm{L}$. & Jatobá \\
\hline Hymenaea parvifolia Huber & jatobá-mirim \\
\hline \multicolumn{2}{|l|}{ Ingaedulis Mart. } \\
\hline Samanea tubulosa (Bent.) Barneby \& J. W. Grimes & sete casca \\
\hline Schizolobiump arabyba var. amazonicum (Huber ex Ducke) & pinho cuiabano \\
\hline Senna alata(L.) Roxb. & angico de pastagem \\
\hline HYPERICACEAE & angico do brejo \\
\hline Vismia guianensis(Aubl.) Choisy & Lacre \\
\hline \multicolumn{2}{|l|}{ LAMIACEAE } \\
\hline Vitex sp. & Tarumã \\
\hline \multicolumn{2}{|l|}{ LAURACEAE } \\
\hline Melizalaurus itauba (Meisn.) Taub. ex Mez & Itaúba \\
\hline \multicolumn{2}{|l|}{ LECYTHIDACEAE } \\
\hline Cariniana sp. & Jequitibá \\
\hline \multicolumn{2}{|l|}{ LYTHRACEAE } \\
\hline Lafoensia sp. & Mirindiba \\
\hline \multicolumn{2}{|l|}{ MALVACEAE } \\
\hline Apeiba tibourbou Aubl. & pente de macaco \\
\hline Ceiba pentandra (L.) Gaerth. & Sumaúma \\
\hline Ceiba speciosa (A. St.-Hil.) Ravenna & Paineira \\
\hline Guazuma ulmifolia Lam. & Mutamba \\
\hline Theobroma speciosum Willd. ex Spreng. & Cacaui \\
\hline \multicolumn{2}{|l|}{ MELIACEAE } \\
\hline Cedrela fissilis Vell. & Cedro \\
\hline Cedrela odorata L. & cedro rosa \\
\hline Swietenia macrophylla King & Mogno \\
\hline \multicolumn{2}{|l|}{ MYRTACEAE } \\
\hline Myrciaria dubia (Kunth) Mc Vaugh & Сатисати \\
\hline Psidium guajava L. & Goiaba \\
\hline \multicolumn{2}{|l|}{ RUBIACEAE } \\
\hline Genipa americana L. & Jenipapo \\
\hline \multicolumn{2}{|l|}{ RUTACEAE } \\
\hline Zanthoxylum fagara (L.) Sarg. & mamica de porca \\
\hline \multicolumn{2}{|l|}{ SAPINDACEAE } \\
\hline Sapindus saponaria $\mathrm{L}$. & olho de indio \\
\hline \multicolumn{2}{|l|}{ SOLANACEAE } \\
\hline Solanum crinitum Lam. & Lobeira \\
\hline \multicolumn{2}{|l|}{ URTICACEAE } \\
\hline Cecropia sp. Loefl. & Embaúba \\
\hline Cecropia purpurascens C. C. Berg & Embaúba-roxa \\
\hline
\end{tabular}

A preparação da área foi iniciada no meio da estação seca e continuou até o início das chuvas, quando o plantio foi feito. A primeira atividade foi o monitoramento e controle de formigas cortadeiras com o uso de iscas formicidas. Em seguida, a área foi submetida ao sobrepastoreio para redução da biomassa das gramíneas, sendo realizadas até cinco operações de gradagem para controle de gramíneas e incorporação de calcário. A última operação de gradagem foi realizada pelo menos 15 dias antes do plantio. No plantio aplicamos, por berço de plantio, $150 \mathrm{~g}$ de fertilizante formulado NPK 05:25:15 e solução de $500 \mathrm{ml}$ com hidrogel polimérico. Após 30 dias, avaliamos a sobrevivência e realizamos o replantio. A manutenção das gramíneas ocorreu pela limpeza em torno das mudas (coroamento) e corte semimecanizado entre as linhas de plantio e entre plantas. Foi realizada a fertilização de cobertura com formulação NPK 
20:05:20. Todas as atividades operacionais necessárias para a restauração são detalhadas em Silveira et al. (2017).

A implantação ocorreu em novembro de 2013 em 12 ha de APPD, na qual utilizamos três estratégias de restauração (Figura 2): i) Plantio em área total (PAT), na qual foi realizada o plantio de mudas em área total no espaçamento $3 \times 2 \mathrm{~m}$; ii) Semeadura direta (SD), no qual foi realizado o plantio de sementes na área total; iii) Ilhas de Diversidade (ID), que consistiu no plantio de mudas de espécies no espaçamento 0,5x0,5m arranjados em módulos adensados e dispostos na área. A implantação ocorreu em espaços delimitados ao longo das APPD, que foram distribuídas de forma aleatória ao longo das áreas a serem restauradas, com 6 ha sendo destinados ao Plantio em Área Total, 3 ha para a Semeadura Direta e 3 ha para as Ilhas de Diversidade.

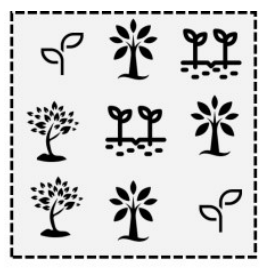

Plantio de mudas em área total (PAT)
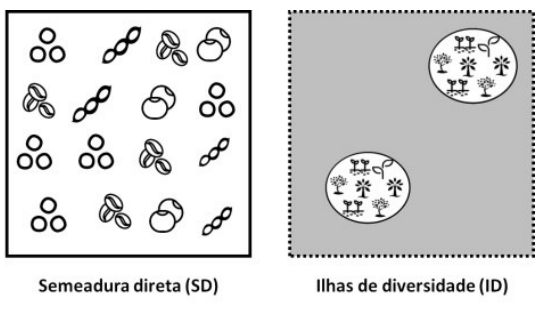

Ilhas de diversidade (ID)
Figura 2. Esquema das 3 estratégias de implantação utilizadas na recuperação das áreas degradadas da Fazenda São Nicolau, Amazônia, Brasil.

Figure 2. Scheme of the 3 implantation strategies used in the recovery of degraded areas at Fazenda São Nicolau, Amazonia, Brazil.

\subsection{Monitoramento e coleta de dados}

O monitoramento foi realizado em julho de 2016 (32 meses - 2,5 anos após a implantação), no qual foram delimitadas 24 unidades amostrais de $10 \times 30 \mathrm{~m}$ no tratamento Plantio em Área Total, 10 unidades amostrais no tratamento de Semeadura Direta e 24 unidades amostrais no tratamento Ilhas de Diversidade, totalizando 58 unidades amostrais (1,74 ha total). Em cada unidade amostral, contabilizamos o número de indivíduos vivos, o número de fustes existentes, bem como sua altura (m), circunferência e área de copa. A altura foi mensurada através de uma régua telescópica com altura limite de 7 metros, sendo considerada a altura entre do nível do solo até a parte vegetativa terminal do indivíduo. Para a mensuração da circunferência adotamos a medida de CAS (circunferência a altura do solo) para indivíduos com altura menor que 1,30, e a medida de Circunferência a Altura do Peito (CAP - Circunferência a 1,30 $\mathrm{m}$ do nível do solo) para indivíduos com altura igual ou superior a 1,30 m. A área de copa foi obtida de duas formas em função das condições operacionais encontradas em campo. Para as estratégias Plantio em Área Total a Ilhas de Diversidade, a área de copa $\left(\mathrm{m}^{2}\right)$ do indivíduo foi obtido através da mensuração com o auxílio da régua telescópica de duas medidas de seu diâmetro, uma paralela a linha de plantio (DC1) e outra perpendicular a esta mesma linha (DC2), paralela assim a entrelinha do plantio. Com estes dois diâmetros, calculamos a área de copa $\left(\mathrm{m}^{2}\right)$ através da fórmula $\mathrm{AC}=\left\{[(\mathrm{DC} 1+\mathrm{DC} 2) / 2]^{\wedge} 2\right\} *(\pi / 4)$.

Já para a estratégia de Semeadura Direta foi considerada a área de copa total da parcela como sendo o produto entre a largura e o comprimento da projeção do conjunto de copas em cada linha de semeadura. A adoção deste método para a Semeadura direta ocorreu devido a elevada densidade de indivíduos recrutados nas parcelas, o que gerou uma sobreposição de copas que impossibilitou a mensuração individual de árvores isoladas. Os indivíduos vivos foram ainda identificados em nível de espécie seguindo a APG IV (2016), sendo parte da identificação realizada em campo e parte mediante coleta de materiais vegetativos e reprodutivos.

\subsection{Análise de dados}

As análises consistiram em avaliar a existência de diferenças entre as três estratégias quanto às seis variáveis resposta: i) número de indivíduos vivos (ind./ha); ii) intensidade de perfilhamento (número de fustes*100/número de indivíduos); iii) Diâmetro médio individual (cm); iv) altura média individual (m); v) Biomassa Arbórea Acima do Solo (Mg) (Above-Ground Woody Biomass-AGWB); vi) área de copa $\left(\mathrm{m}^{2} / \mathrm{ha}\right)$. Para testar a existência de diferenças utilizamos Modelos Lineares Generalizados (GLM) com posterior teste post-hoc Lsmeans (Lenth; Lenth, 2018) ao nível de 5\% de significância em caso de existência de diferenças significativas. Todas as variáveis foram trabalhadas dentro da distribuição de resíduos gaussian com função de ligação identity, atendendo aos critérios de homocedasticidade e normalidade dos resíduos. A AGWB foi obtida através do pacote biomass (Rejou-Mechain et al., 2017), utilizando a equação pantropical de Chave et al., (2014), a partir dos dados de diâmetro (obtidos através da circunferência), de altura individual e de dados de densidade da madeira obtidas no banco de dados do pacote (Global Wood Density data base). Todas as análises foram realizadas no programa R Studio v. 3.5.2 (2018).

Nós quantificamos ainda o Valor de Cobertura (\%) de cada espécie inventariada em cada uma das três estratégias, considerando a sua densidade (ind./ha) e AGWB (ton./ha) absolutos. O valor de cobertura é uma medida obtida em função da importância relativa da espécie quanto a densidade de indivíduos e biomassa (AGBW), oferecendo informações sobre padrões de dominância e importância específicas para a comunidade. Com base nos resultados, exploramos quais as espécies dominantes em cada uma das estratégias, considerando $50 \%$ do Valor de Cobertura como critério de corte, com o objetivo de avaliar suas aptidões às diferentes condições de cada estratégia. Por fim, avaliamos como o Valor de Cobertura apresentado pelos conjuntos de espécies dominantes de cada estratégia se comportou nas demais estratégias. Esta avaliação foi realizada através da quantificação do valor de cobertura total apresentado pelas espécies dominantes de cada condição quando inventariadas nas demais estratégias.

\section{RESULTADOS}

Para a variável número de indivíduos vivos, a estratégia Semeadura direta apresentou os valores significativamente maiores $(\mathrm{p}<0.05)$, seguido pelo Plantio em Área Total e pelas Ilhas de diversidade, com os menores valores (Figura 3 esquerda). Tal padrão não ocorreu para a variável Intensidade de Perfilhamento, que foi significativamente maior na estratégia de Ilhas de Diversidade, seguida pela Semeadura Direta e pelo Plantio em Área Total com os menores valores (Figura 3 - direita). Com relação às variáveis morfométricas Diâmetro médio (cm) e Altura média (m) (Figura 4), as estratégias apresentaram valores similares que não se diferenciaram significativamente entre si ( $\mathrm{p}>0.05)$.

Para as variáveis Biomassa Arbórea Acima do Solo (AGWB) e para Área de copa (AC) (Figura 5), a estratégia por Semeadura direta apresentou valores significativamente 
maiores que os das outras estratégias $(p<0.05)$. Contudo, enquanto para AGWB as estratégias Ilhas de Diversidade e Plantio em Área Total não se diferenciaram significativamente. Para Área de Copa, o Plantio de Área Total apresentou valores significativamente maiores que os apresentados pela estratégia por Ilhas de Diversidade. Assim, a estratégia por Semeadura Direta se destacou como sendo a estratégia com maior densidade, biomassa e ocupação da área, não estando tais resultados associados a indivíduos mais perfilhados.
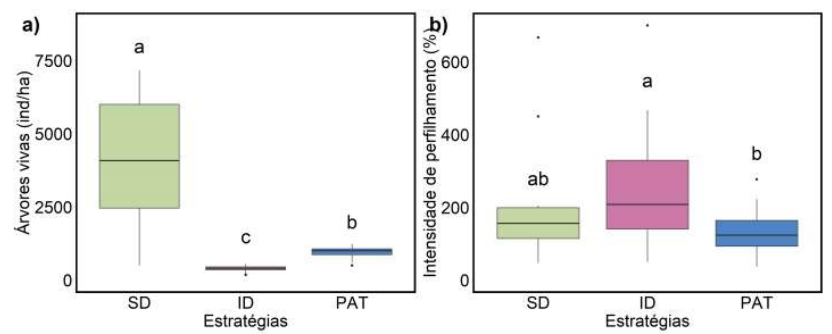

Figura 3. Número de indivíduos vivos por ha (Figura a esquerda) e Intensidade de perfilhamento (\%) para as três estratégias de implantação de florestas utilizadas na Fazenda São Nicolau, Amazônia, Brasil. Nota: SD: Semeadura direta; ID: Ilhas de Diversidade; PAT: Plantio em Área Total. Tratamentos seguidos pelas mesmas letras não se diferenciam pelo teste LsMeans ao nível de $5 \%$ de significância.

Figure 3. Number of living individuals per ha (figure on the left) and resprouting intensity (\%) for the three forest implantation strategies used at Fazenda São Nicolau, Amazônia, Brazil. Note: SD: Direct seeding; ID: Islands of Diversity; PAT: Total Area Planting. Treatments followed by the same letters are not differentiated by the LsMeans test at the $5 \%$ significance level.
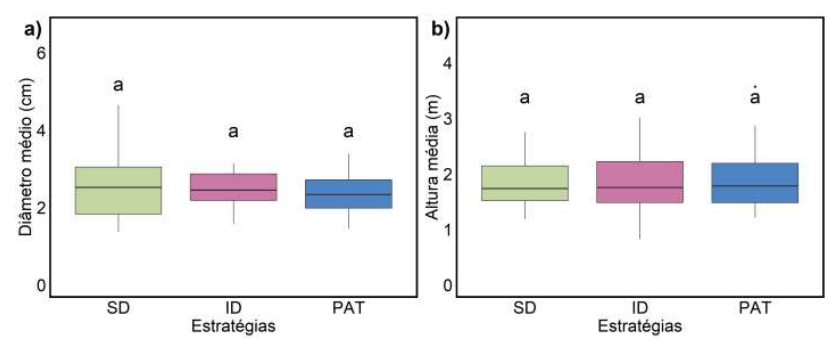

Figura 4. Diâmetro médio $(\mathrm{cm})$ (Figura a esquerda) e altura média $(\mathrm{m})$ (Figura a direita) de indivíduos para as três estratégias de implantação de florestas utilizadas na Fazenda São Nicolau, Amazônia, Brasil. Nota: SD Semeadura direta; ID: Ilhas de Diversidade; PAT: Plantio em Área Total, Tratamentos seguidos pelas mesmas letras não se diferenciam pelo teste LsMeans ao nível de $5 \%$ de significância.

Figure 4. Average diameter $(\mathrm{cm})$ (figure on the left) and average height (m) (figure on the right) of individuals for the three forest implantation strategies used at Fazenda São Nicolau, Amazonia, Brazil. Note: SD Direct seeding; ID: Islands of Diversity; PAT: Total Area Planting. Treatments followed by the same letters are not differentiated by the LsMeans test at the $5 \%$ significance level.

A estratégia por Plantio em Área Total apresentou os resultados intermediários, enquanto as Ilhas de Diversidade apresentaram a menor densidade, biomassa e ocupação de área, em associação com maior adoção do perfilhamento como estratégia de ocupação dos indivíduos.

As espécies dominantes de cada estratégia apresentaram desempenhos acentuadamente distintos, com as espécies da estratégia de Semeadura Direta apresentando valores de densidade absoluta e AGWB consideravelmente superiores aos apresentados pelas espécies das estratégias de Ilhas de Diversidade e Plantio em Área Total, mais similares entre si (Tabela 2 e Figura 6).
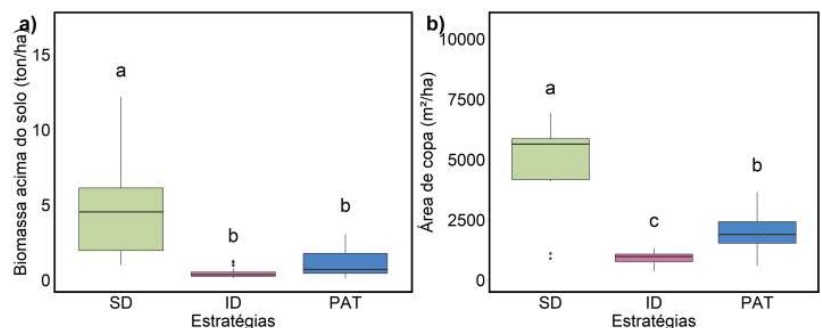

Figura 5. Biomassa do estrato arbóreo acima do solo (AGWB - ton. / ha) (Figura a esquerda) e Área de copa $\left(\mathrm{m}^{2}\right)$ (Figura a direita) para as três estratégias de implantação de florestas utilizadas na Fazenda São Nicolau, Amazônia, Brasil. Nota: SD: Semeadura direta; ID: Ilhas de Diversidade; PAT: Plantio em Área Total. Tratamentos seguidos pelas mesmas letras não se diferenciam pelo teste LsMeans ao nível de $5 \%$ de significância.

Figure 5. Above ground soil biomass (AGWB - ton. / Ha) (figure on the left) and crown area $\left(\mathrm{m}^{2}\right)$ (figure on the right) for the three forest implantation strategies used at Fazenda São Nicolau, Amazônia, Brazil. Note: SD: Direct seeding; ID: Islands of Diversity; PAT: Total Area Planting. Treatments followed by the same letters are not differentiated by the LsMeans test at the $5 \%$ significance level.

Tabela 2. Densidade Absoluta (DA) e Biomassa Arbórea Acima do Solo (AGWB) das espécies mais representativas em Valor de Cobertura (CV), considerando $50 \%$ como critério de corte, para as três estratégias de implantação utilizadas na Fazenda São Nicolau, Amazônia, Brasil.

Table 2. Absolute Density (AD) and Above Ground Tree Biomass (AGWB) of the most representative species in Coverage Value (CV), considering $50 \%$ as the cutoff criterion, for the three implantation strategies used at Fazenda São Nicolau, Amazônia, Brazil.

\begin{tabular}{|c|c|c|c|c|}
\hline & Espécies & $\begin{array}{c}\text { DA } \\
\text { (ind/ha) }\end{array}$ & $\begin{array}{c}\text { AGWB } \\
\text { (ton./ha) }\end{array}$ & $\begin{array}{l}\mathrm{CV} \\
(\%)\end{array}$ \\
\hline \multirow{4}{*}{ SD } & Senna alata & 850.00 & 1.01 & 20.44 \\
\hline & Cajanus cajan & 583.33 & 0.96 & 16.68 \\
\hline & Bixa orellana & 666.67 & 0.35 & 11.75 \\
\hline & Baubinia rufa & 350.00 & 0.75 & 11.71 \\
\hline \multirow{6}{*}{ ID } & Guazuma ulmifolia & 61.25 & 0.07 & 15.71 \\
\hline & Hymenaea courbaril & 47.50 & 0.03 & 9.74 \\
\hline & Baubinia rufa & 21.25 & 0.06 & 8.79 \\
\hline & Inga vera & 25.00 & 0.04 & 7.47 \\
\hline & Handroanthus impetiginosus & 17.50 & 0.05 & 7.41 \\
\hline & Pseudima frutescens & 12.50 & 0.05 & 6.72 \\
\hline \multirow{6}{*}{ PAT } & Guazuma ulmifolia & 197.22 & 0.17 & 18.45 \\
\hline & Baubinia rufa & 63.89 & 0.12 & 8.77 \\
\hline & Genipa americana & 95.83 & 0.06 & 7.60 \\
\hline & Leucaena leucocephala & 16.67 & 0.13 & 6.77 \\
\hline & Handroanthus serratifolius & 52.78 & 0.07 & 6.24 \\
\hline & Citharexylum poeppigii & 38.89 & 0.07 & 5.20 \\
\hline
\end{tabular}

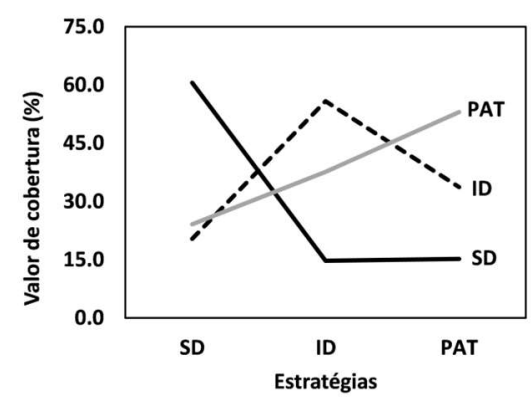

Figura 6. Valor de cobertura (\%) apresentado pelas espécies dominantes ( $50 \%$ do CV) de cada estratégia (SD, ID e PAT) nas demais estratégias utilizadas na Fazenda São Nicolau, Amazônia, Brasil. Como exemplo, os valores da linha preta não contínua correspondem aos CV apresentado pelas espécies dominantes da estratégia SD na estratégia SD, ID e PAT. Nota: SD: Semeadura direta; ID: Ilhas de Diversidade; PAT: Plantio em Área Total.

Figure 6. Coverage value (\%) presented by the dominant species $(50 \%$ of CV) for each strategy (SD, ID and PAT) in the other strategies used at Fazenda São Nicolau, Amazônia, Brazil. As an example, the values of the non-continuous black line correspond to the CVs presented by the dominant species of the SD strategy in the SD, ID and PAT strategy. Note: SD: Direct seeding; ID: Islands of Diversity; PAT: Total Area Planting. 


\section{DISCUSSÃO}

Nossos resultados apontaram que na idade avaliada as estratégias se diferenciam quanto a sua efetividade, apresentando diferenças em variáveis associadas a ocupação do espaço e forma de ocupação (Densidade, Biomassa, área de copa e perfilhamento), porém sem diferenças no desempenho específico de indivíduos (Diâmetro e Altura média). Cada uma delas apresentou um conjunto diferenciado de espécies de sucesso, sendo tal diferença uma resposta às diferentes restrições oferecidas por cada estratégia,

O destaque da estratégia Semeadura Direta para a variável densidade de indivíduos provavelmente está associado à densidade de semeadura utilizada, e aos fatores ambientais, ecológicos, e de planejamento e execução da técnica. A densidade de indivíduos também foi elevada (média de 4200 plantas por hectare) em áreas de restauração florestal mediante semeadura direta aos 10 anos no estado de Mato Grosso devido a elevada densidade de sementes, riqueza de espécies, diferentes grupos funcionais (FREITAS et al., 2019). Os autores argumentam que esses aspectos resultaram em uma floresta estratificada com alta densidade de indivíduos, alta relação altura / diâmetro e que não se bifurcam nos primeiros anos e formam rapidamente uma floresta secundária alta, porém, assim como em nosso estudo foi contatado variação substancial nos resultados obtidos. Portanto, a semeadura direta se mostra como uma técnica efetiva na ocupação dessas áreas mediante a conjunção favorável dos fatores mencionados, porém, sua utilização pode resultar em insucesso caso as condições não sejam adequadas.

A elevada densidade de plantas germinadas na semeadura direta deve-se especialmente as espécies utilizadas para atuarem como adubos verdes (Cajanus cajan e Senna alata). Essas espécies germinaram e se estabeleceram de modo a criarem uma estrutura florestal. Essa estruturação e cobertura pode criar condições especificas de clima em nível local e possibilitar com isso a colonização por facilitação de espécies de grupos florísticos e faunísticos mais exigentes (LUGO, 1997; TUCKER; MURPHY, 1997). A cobertura cria um micro-habitat florestal, sendo determinante na continuidade dos processos de sucessão secundária (De MELO et al., 2007). Apesar de não ter sido avaliada, durante a coleta de dados foi constatada a germinação de sementes das outras espécies nas áreas tratadas com a semeadura direta, o que mostra que o recrutamento está ocorrendo. Assim, sugere-se acompanhamento de longo prazo de estudos dessa natureza, e o monitoramento da regeneração natural para inferir sobre a sucessão nessas áreas. O recrutamento de espécies mediante regeneração natural sob o dossel formado por essas espécies também deve ser mais bem avaliado.

A regeneração natural é um aspecto pouco investigado acerca da restauração florestal com o uso da semeadura direta (FREITAS et al., 2019). A elevada densidade de plantas pode levar a formação de populações monodominantes com um dossel uniforme, e que por inibição podem levar a uma estagnação ou mesmo retrocesso na estruturação florestal e sucessão ecológica dessas comunidades, e essa situação, em função de cada caso pode ser transitória e formar áreas extremamente sombreadas (URIARTE; CHAZDON, 2016). O contexto de paisagem e de mudanças climáticas podem afetar no uso e consolidação da estratégia de restauração, pois, na área de estudo a matriz é permeável. Na paisagem, o destaque são os maciços de florestas naturais em estágio avançado de conservação, os reflorestamentos do poço de carbono florestal e as florestas secundárias em diferentes estágios de regeneração. Segundo Palma; Laurence (2015) entre o plantio de sementes ou mudas, a semeadura direta pode ser mais vulnerável a extremos climáticos, particularmente em ecossistemas tropicais, e pode ser restrita a locais com vegetação existente.

O destaque da estratégia SD no estoque de biomassa, e consequentemente no estoque de carbono, e na cobertura de copa está diretamente associada a elevada densidade de indivíduos que germinaram e conseguiram se estabelecer na área, e que devido a sua maior quantidade proporcionaram os maiores valores observados para essas características. Uma importante e articulada ação de restauração em larga escala de florestas tropicais mediante a semeadura direta é a iniciativa Y Ikatu Xingu que, além da escala, de destaca pela organização e engajamento social (DURIGAN et al., 2013). Áreas em restauração via semeadura direta oriundas desse projeto foram avaliadas com idade de 01 a 10 anos por Freitas et al. (2019), e foram comparadas por variáveis estruturais da ecologia da vegetação. A semeadura se mostrou uma excelente técnica para iniciar o processo de restauração, e também se destacou com densidade, cobertura de copa e os maiores estoques de biomassa acima do solo, porém, também foi notado comportamento acentuadamente variado entre os resultados obtidos, assim como observado no presente estudo.

Apesar do destaque da SD na promoção da cobertura de copa, nessas áreas ainda há porções ocupadas por pastagens, tais situações são notadas principalmente em porções das áreas onde a semeadura não teve sucesso na germinação e consequentemente ocupação da área. Possivelmente aspectos como encharcamento natural do solo e incidência de capim sejam fatores locais de insucesso e variação nos resultados da técnica. Assim como a qualidade das sementes e condições necessárias à germinação e estabelecimento das plantas (PALMA; LAURENCE, 2015; GROSSNICKLE; IVETIĆ, 2017).

Na Mata Atlântica, um domínio altamente ameaçado, a análise de muitos projetos anteriores de restauração florestal mostrou que muitos não resultaram em florestas que se autoperpetuam e, atualmente, com o apoio da comunidade científica, a maioria dos projetos visa a construção de florestas autossustentáveis. As experiências mostraram que a restauração florestal com alta diversidade é viável, mas depende das estratégias aplicadas e da paisagem circundante. Os avanços técnicos são continuamente produzidos e são incorporados em diferentes intensidades. No entanto, os principais desafios para consolidar a atividade são a redução de custos, o planejamento de ações em nível paisagístico e questões sociopolíticas (RODRIGUES et al., 2009). Esses temas também são barreiras para a efetivação e ampliação da restauração ecológica nas áreas da Amazônia, Cerrado e Caatinga, entre outros aspectos do domínio analisado.

A semeadura direta é tida como uma técnica de baixo custo (Engel; Parrotta, 2001; Campos-Filho et al., 2013; Palma; Laurence, 2015; Grossnickle; Ivetić, 2017; Freitas et al., 2019), o investimento na implantação da técnica pode variar na média de 30 a 38\% do custo total com o plantio de mudas de raízes nuas ou em recipientes, respectivamente (GROSSNICKLE; IVETIĆ, 2017). A perspectiva de menor desembolso proporcionaria maior adesão de proprietários rurais na restauração florestal e as variações no custo fortemente dependentes do preço das sementes e taxa de 
semeadura (GROSSNICKLE; IVETIĆ, 2017; PALMA; LAURENCE, 2015). A metodologia figura como promissora para alancar os esforços em restauração e assim possibilitar os ganhos de escala para a atividade, segundo proposto por iniciativas internacionais e nacionais como o Bonn Challenger e o Plano Nacional de Recuperação da Vegetação Nativa (PLANAVEG), do governo brasileiro, que buscam usar dos reflorestamentos da restauração para enfrentar às mudanças climáticas e perda da diversidade (HOLL; ZAHAWI, 2014; POORTER et al., 2016; FREITAS et al., 2019). A técnica foi caracterizada por Freitas et al. (2019) como um método bemsucedido para a fase inicial de restauração florestal, promovendo uma estrutura mais semelhante aos locais resilientes e em regeneração natural, do que aqueles não resilientes e em regeneração ou aqueles em que foram usados o plantio de mudas.

O plantio em área total (PAT), e as ilhas de diversidade (ID) proporcionaram resultado semelhantes também para o estoque de biomassa calculado a partir dessas características. Possivelmente esse comportamento seja devido ao controle da densidade de plantas em função da utilização de mudas em tais metodologias. O uso de mudas como propágulos, apresenta como benefícios na restauração: a possibilidade de propagação e estabelecimento efetivo de espécies ameaçadas de extinção ou que produzam poucas sementes (Brancalion et al., 2010). O plantio em área total é indicado para locais com pouca vegetação remanescente e baixa capacidade de resiliência, porém tendem a apresentar custo elevado (CAVA et al., 2016). Em situações marcadas pela existência de árvores isoladas na paisagem e remanescentes próximos as ilhas de diversidade podem ser o método mais atrativo, pois, além de proporcionar resultados parecidos ao plantio em área total, a implantação e manutenção é menos onerosa e apresenta maior rendimento por ser implementadas em porções pontuais das áreas.

A maior intensidade de perfilhamento observada nas Ilhas de Diversidade em relação às demais estratégias, provavelmente se relaciona às características ecológicas associadas a esta estratégia, principalmente atreladas a competição por luz e modificações na configuração estrutural da paisagem. As técnicas de nucleação proporcionam um aumento da biodiversidade local e se apresenta como uma das melhores formas de implementar a sucessão dentro de áreas degradadas (REIS et al., 2010). As Ilhas de Diversidade compreendem núcleos pontuais em que as espécies são implantadas em módulos adensados, logo, estes núcleos configuram condições internas distintas às observadas na matriz adjacente quanto: ao sombreamento, interceptação de precipitação e estabilidade do solo. Adicionalmente, esta estratégia necessita após a implantação de práticas de manejo menos intensivas, com fatores importantes como o controle de gramíneas e outras plantas potencialmente danosas às mudas implantadas realizado pontualmente em cada um dos núcleos e não em área total. Estes atributos tornam as Ilhas de Diversidade locais menos restritivos localmente em relação matriz adjacente para o estabelecimento de indivíduos, porém fazem com que o sucesso relativo dos mesmos seja efetivo mediante a superação dos outros indivíduos imediatamente próximos, principalmente no que se refere a interceptação de luz. Assim, a técnica seria a estratégia com maior restritividade biótica por competição, onde os indivíduos têm o seu estabelecimento atrelado a própria existência do núcleo, e seu sucesso relativo associado ao desempenho na utilização dos recursos. Neste sentido, a maior frequência de adoção do perfilhamento como estratégia de desenvolvimento seria uma resposta a esta maior competição, onde os indivíduos investem recursos na emissão de novos brotos que formarão copas que auxiliarão na assimilação de recursos (BOND; MIDGLEY, 2001; PAUSAS; KEELEY, 2014).

O perfilhamento consiste na emissão de novos brotos vegetativos mediante alocação de recursos não estruturais acumulados na planta, em ocasião de distúrbios ou agentes que afetem a sobrevivência ou o sucesso de indivíduos (MOREIRA; TORMO, 2012). Estes fatores podem estar associados a escassez hídrica, fogo, inundação, patógenos, vento, toxidez do solo, ações antrópicas e competição de recursos (BOND; MIDGLEY, 2001; BOND; MIDGLEY, 2003; ZEPPEL et al., 2015; PAUSAS et al., 2016). Nestas situações, o indivíduo deixa de investir recursos em reprodução sexuada para aloca-los no desenvolvimento de brotos que podem contribuir para a sobrevivência e para o sucesso no local (BOND; MIDGLEY, 2001; MOREIRA; TORMO, 2012). Este processo de investimento diferencial que resulta no perfilhamento está relacionado a um conjunto de traços fisiológicos e anatômicos desenvolvidos pelas espécies e linhagens ao longo dos processos evolutivos, que o compõem o seu "nicho de persistência" (BOND; MIDGLEY, 2001; BOND; MIDGLEY, 2003; PAUSAS et al., 2016). Esta estratégia tem sido tratada por diversos autores como um atributo essencial para os padrões ecológicos em florestas tropicais, sendo parte indissociável do desenvolvimento de plantas em ambientes que oferecem restrições ecológicas nas diversas fases sucessionais, sendo consequentemente um processo importante nos processos de restauração e nas respostas da vegetação a modificações ambientais (ZEPPEL et al., 2015; PAUSAS et al., 2016).

Outro resultado importante encontrado em nosso estudo foi a ausência de diferenças entre os tratamentos quando ao crescimento em altura e diâmetro. De acordo com Scolforo (2006), o crescimento em altura das árvores sofre influência do genótipo e do sítio. A variação do mesmo foi relativamente similar entre as técnicas, possivelmente por ser um atributo limitado pelos fatores condicionantes locais. Em estudos das ciências florestais, o crescimento em altura é bastante utilizado visto que este descreve o potencial de crescimento e produtividade dos sítios florestais, seja em plantios puros ou mistos (MCDILL; AMATEIS, 1992; VANCLAY, 1994; SCOLFORO, 2006; DEL RÍO et al., 2016; HENTTONEN et al., 2017).

A idade dos plantios e o elevado status competitivo com a população de gramíneas exóticas estabelecidas nas áreas ajudam a explicar o crescimento em altura. Assim, apesar da reconhecida importância de aspectos nutricionais, esses, possivelmente tiveram importância menor no crescimento das mudas. Segundo Campbell et al. (1991), a competição permanece ativa em condições de grave perturbação, porém, os efeitos diretos da fertilidade diminuem em importância na produção das plantas. As áreas em que as estratégias foram implantadas tratam-se, em sua maioria, de solos pobres com histórico de abertura mediante uso de fogo. Nestas regiões ocorre o avanço do desmatamento sob a floresta amazônica para a prática de pecuária (BERNARDES et al., 2017).

Cada técnica de restauração apresentou um conjunto único de espécies dominantes, e foram essas que possivelmente mais contribuíram para o desempenho diferenciado nas características avaliadas para as estratégias estudadas. Isso mostra que as espécies, quando utilizadas em 
projetos de restauração podem apresentar resultados distintos no estabelecimento e ocupação dessas áreas e ao longo da mesma. Assim, o conhecimento das espécies em função da(s) estratégia(s) que maximiza seu desempenho em se estabelecer e ocupar tais ambientes é imprescindível. Isso significa dizer que toda espécie pode ser utilizada na restauração florestal, porém, há que se conhecer em quais técnicas essas apresentam melhor adaptabilidade e contribuem mais efetivamente para a estruturação da comunidade florestal.

Em função de suas características ecológicas, as espécies podem interagir de forma positiva ou negativa com as condições ambientais e operacionais impostas pela estratégia, de forma a influenciar o sucesso no estabelecimento e ocupação. Por exemplo, a escolha de espécies para estratégias associadas a implantação por mudas deve considerar que filtros ecológicos presentes nas etapas de germinação e desenvolvimento de plântulas já terão sido vencidos, com a muda já apresentando sistema radicular desenvolvido (PAKKAD et al., 2003). Já o pool implantado em estratégias como a de Semeadura Direta deve conter espécies que possam se adequar a estes filtros, assim como a competição inicial com outras espécies e com gramíneas (GROSSNICKLE; IVETIĆ, 2017; PALMA; LAURENCE, 2015). Assim, a relação entre as condições ambientais de cada estratégia e as espécies implantadas ocorrem dentro de uma interação com feedback positivo e negativo de influências, em que as condições influenciam o desenvolvimento das espécies e as espécies influenciam a efetividade da estratégia no estabelecimento e ocupação (ELLIOT et al., 2003).

$\mathrm{Na}$ Amazônia algumas poucas espécies nativas são conhecidas o suficiente para serem recomendadas em programas de reabilitação e restauração florestal de áreas degradadas. Várias espécies nativas parecem estar bem adaptadas às condições climáticas extremas, baixa fertilidade do solo e intensa competição por recursos escassos presentes em locais degradados, mas poucos destas foram estudadas (CAMARGO et al., 2002). Apesar do avanço nos estudos da biodiversidade da floresta tropical amazônica, a situação de escassez e deficiência de informações dessas espécies persiste nos dias atuais.

Algumas espécies chamaram atenção pela sobrevivência e desempenho do crescimento em altura e área de copa observado em campo. A espécie Senna alata está entre as espécies com melhor desenvolvimento, e representa quase $20 \%$ dos indivíduos inventariados. Essa espécie possui crescimento extremamente rápido, reprodução precoce e é atrativa a fauna especialmente abelhas e mamangavas, bem como, para pecuária é considerada uma planta daninha por prejudicar o desenvolvimento do capim (RODRIGUES, 2010). A espécie apresenta destacada tendência ao perfilhamento e a formação de indivíduos com múltiplos fustes, destacado crescimento em diâmetro e área de copa. Já Senna multijuga figura entre as com maior potencial, pois apresenta rápido crescimento em altura, reprodução "precoce", excelente formação de copa e atração a fauna. Outras espécies que se destacaram foram Guazuma ulmifolia e Baubinia rufa que também apresentaram elevada sobrevivência, ritmo de crescimento inicial elevado e reprodução a partir do primeiro ano, no entanto, o crescimento em altura e área de copa é menor quando comparada com as espécies Senna. Bixa orellana e Anacardium ocidentale também se destacaram no crescimento em altura e área de copa, essas espécies apresentaram também reprodução de muitos indivíduos no primeiro e especialmente no segundo ano de monitoramento. Já Solanum crinitum, a lobeira, apresentou o mesmo padrão, no entanto, foi verificada alta mortalidade de muitos indivíduos, já no segundo ano.

Outro ponto importante a ser discutido é a presença da espécie Leucaena leucocephala relatada como espécie invasora e com enormes prejuízos a diversidade (COSTA; DURIGAN, 2010). A espécie foi utilizada em projetos de restauração no Brasil, e os talhões de leucena melhoram as propriedades do solo, oferecem proteção contra erosão e assoreamento, fixam carbono atmosférico e até oferecem abrigo para a fauna, mas deixam a desejar em termos de recuperar a diversidade de plantas nativas (SOUZA; DURIGAN, 2013). Assim, é preciso precaução na escolha de espécies, bem como, além da regeneração natural nessas áreas há que se atentar para o potencial invasor das espécies utilizadas. Se necessário, práticas de manejo adaptativo que busquem o controle da população indesejada para o alcance das metas estabelecidas.

A evolução da restauração de florestas tropicais no Brasil foi marcada pela experimentação, e pela avaliação de práticas realizadas com vistas a avançar no processo e assim foram se quebrando paradigmas. A pesquisa aqui relatada também auxiliou no aperfeiçoamento da prática de restauração de matas ciliares na área de estudo e região, e com os aprendizados oriundos da prática 72 hectares estão em processo desde 2013, dos quais mais a maioria mediante o plantio de mudas. A seleção de um grupo diverso de espécies que se destacaram pela sobrevivência e crescimento nas diferentes fases do processo nos anos iniciais proporcionou redução da mortalidade de mudas para aproximadamente $10 \%$ aos dois anos após plantio. Tal redução foi acompanhada do adiantamento no tempo requerido para fechamento de copas das árvores e sombreamento da área, no final do segundo ano após plantio, e que refletiu na redução dos custos de manutenção com limpezas e roçadas. Os resultados do programa de restauração conduzido e as experiências adquiridas e vivenciadas no processo foram sistematizados por Silveira et al., 2017, no formato de um guia de boas práticas de restauração de matas ciliares na região, o material já foi utilizado em práticas de capacitação em restauração florestal na região, e em ações de educação ambiental. Além da versão impressa o material encontra-se disponível no sitio eletrônico: http://petra.eco.br/guia-deboas-praticas-restauracao-de-areas-de-preservacaopermanente-degradadas-appds/.

Nossos resultados mostraram que as estratégias se diferenciam quanto a efetividade em relação ao estabelecimento e ocupação, com estas diferenças associadas ao contexto ecológico, operacional e as espécies implantadas. Neste sentido, a semeadura direta se apresentou como promissora dentro do contexto estudado, com desempenho superior as demais no estabelecimento e ocupação. Contudo, no geral as espécies presentes são parte importante do processo, sendo um fator diretamente associada a efetividade da estratégia e que deve ser analisado como parte essencial para o sucesso da restauração. Estes resultados somam no conhecimento e pode contribuir para o processo de restauração florestal em florestas tropicais, sobretudo no domínio amazônico. Os ecossistemas deste domínio têm sofrido com o avanço da agropecuária e com a exploração madeireira, apresentando montante de reservas legais e áreas de preservação permanente degradadas superior a oito milhões de hectares (SOARES-FILHO et al., 2014). Este 
processo ameaça a conservação destes ambientes, de sua biodiversidade e de todos os serviços ecossistêmicos essenciais por eles prestados (CARDINALE et al., 2012; PERRING et al., 2015; MITCHARD et al., 2018). Assim, são imprescindíveis estudos que possam contribuir para melhorias no processo de restauração no sentido de potencializar sua efetividade mediante construção de conhecimento sobre diferenças entre estratégias de restauração, espécies e sobre a sua interação (GUARIGUATA; BRANCALION, 2014; PERRING et al., 2015; BRANCALION; Van MELIS, 2017). A restauração florestal é ainda parte importante dos projetos globais de conservação da biodiversidade e da mitigação de efeitos das mudanças climáticas sobre os ambientes terrestres e a sociedade, com a construção de conhecimento a seu respeito devendo ganhar ainda mais importância em um mundo em transformação.

\section{CONCLUSÕES}

A semeadura direta se mostrou como mais efetiva estratégia de restauração devido a rápida ocupação, e da promoção da estrutura florestal devido a elevada germinação e estabelecimento das espécies utilizadas, e que resultou no fechamento de dossel e sombreamento da área, com consequente eliminação de gramíneas exóticas agressivas e acumulo de biomassa destacado. O desempenho das estratégias foi modulado, em grande parte pelo sucesso e atuação diferenciada das espécies, nas técnicas de restauração florestal avaliadas.

Assim, nossos resultados têm potencial de aplicação prática, pois oferece bases para o entendimento do funcionamento e eficiência de técnicas de baixo custo quando comparado ao plantio de mudas, e desse modo, pode auxiliar no ganho de escala da restauração de florestas tropicais, como medida de enfrentamento a mudanças climáticas e conservação da diversidade.

\section{AGRADECIMENTOS}

Agradecemos ao Projeto de Poço de Carbono Florestal da Peugeot-ONF (PCFPO) pelo apoio. A Universidade Federal de Lavras e a Universidade Federal de Mato Grosso, Campus Universitário de Sinop, por oportunidades de qualificação. Coordenação de Aperfeiçoamento de Pessoal de Nível Superior (CAPES) e Fundação de Amparo à Pesquisa do Estado do Mato Grosso pela concessão da bolsa de estudos.

\section{REFERÊNCIAS}

APG_Angiosperm Phylogeny Group IV. An update of the Angiosperm Phylogeny Group classification for the orders and families of flowering plants: APG IV, Botanical Journal of the Linnean Society v. 181, p. 120, 2016. DOI: https://doi.org/10.1111/boj.12385

ASNER, G. P.; RUDEL, T. K.; AIDE, T. M.; DEFRIES, R.; EMERSON, R. A contemporary assessment of change in humid tropical forests. Conservation Biology, v. 23, n. 6, p. 1386-1395, 2009. DOI: $10.1111 / \mathrm{j} .1523-$ 1739.2009.01333.x

BOND, W. J.; MIDGLEY, J. J. Ecology of sprouting in woody plants: the persistence niche. Trends in ecology \& evolution v. 16, n. 1, p. 45-51, 2001. DOI: http://dx.doi.org/10.1016/S0169-5347(00)02033-4
BOND W. J.; MIDGLEY J. J. The evolutionary ecology of sprouting in woody plants. International Journal of Plant Sciences, v. 164, S3, p. S103-S114, 2003. DOI: http://www.jstor.org/stable/10.1086/374191

BONN CHALLENGE. 2009 Bonn Challenger, USA. Disponivel em: http://www.bonnchallenge.org/. Acessado em 15 mar. 2019.

BRANCALION, P. H. S.; MELLO, F. P. L.; TABARELLI, M.; RODRIGUES, R. R. Restoration reserves as biodiversity safeguards in human-modified landscapes. Natureza e Conservação, v. 11, n. 2, p. 186-190, 2013. http://doi.editoracubo.com.br/10.4322/natcon.2013.02 9

BRANCALION, P. H. S.; RODRIGUES, R. R.; GANDOLFI, S.; KAGEYAMA, P. Y.; Nave, A. G.; GANDARA, F. B.; BARBOSA, L. M.; TABARELLI, M. Instrumentos legais podem contribuir para a restauração de florestas tropicais biodiversas. Revista Árvore, v. 34, n. 3, p. 455-470, 2010.

BRANCALION, P. H. S.; Van MELIS, J. On the Need for Innovation in Ecological Restoration1. Annals of the Missouri Botanical Garden, v. 102, n. 2, p. 227-237, 2017. DOI: https://doi.org/10.3417/2016034

IBBE_BRASIL_Instituto Brasileiro de Geografia e Estatística. Manual técnico da vegetação brasileira: sistema fitogeográfico, inventário das formações florestais e campestres, técnicas e manejo de coleções botânicas, procedimentos para mapeamentos. Rio de Janeiro: IBGE - Diretoria de Geociências, 2012. 271p.

CAMARGO, J. L. C.; FERRAZ, I. D. K.; IMAKAWA, A. M. Rehabilitation of degraded areas of central Amazonia using direct sowing of forest tree seeds. Restoration Ecology, v. 10, n. 4, p. 636-644, 2002. DOI: https://doi.org/10.1046/j.1526-100X.2002.01044.x

CAMPBELL, B. D.; GRIME, J. P.; MACKEY, J. M. L.; JALILI, A. The quest for a mechanistic understanding of resource competition in plant communities: the role of experiments. Functional Ecology, v. 5, n. 2, p. 241-253, 1991. DOI: https://doi.org/10.2307/2389262.

CAMPOS-FILHO, E. M.; DA COSTA, J. N.; DE SOUSA, O. L.; JUNQUEIRA, R. G. Mechanized direct-seeding of native forests in Xingu, Central Brazil. Journal of Sustainable Forestry, v. 32, n. 7, p. 702-727, 2013. DOI: https://doi.org/10.1080/10549811.2013.817341

CARDINALE, B. J.; DUFFY, J. E.; GONZALEZ, A.; HOOPER, D. U.; PERRINGS, C.; VENAIL, P.; NARWANI, A.; GEORGINA, M. M.; TILMAN, D.; WARDLE, D. A.; KINZIG, A. P.; DAILY, G. C.; LOREAU, M.; GRACE, J. B.; LARIGAUDERIE, A.; SRIVASTAVA, D. S.; NAEEM, S. Biodiversity loss and its impact on humanity. Nature, v. 486, e7401, p. 59-67, 2012. DOI: https://doi.org/10.1038/nature11148

CAVA, M. G. B.; ISERNHAGEN, I.; MENDONÇA, A. H.; DURIGAN, G. Comparação de técnicas para restauração da vegetação lenhosa de Cerrado em pastagens abandonadas. Hoehnea, v. 43, n. 2, p. 301-315, 2016.

CHAVE, J.; RÉJOU-MÉCHAIN, M.; BÚRQUEZ, A.; CHIDUMAYO, E.; COLGAN, M. S.; DELEITTI, W. B. C.; DUQUE, A.; EID, T.; FEARNSIDE, P. M.; GOODMAN, R. C.; HENRY, M.; MARTÍNEZYRÍZAR, A.; MUGASHA, W. A.; MULLERLANDAU, H. C.; MENCUCCINI, M.; NELSON, B. W.; NGOMANDA, A.; NOGUEIRA, E. M.; ORTIZMALAVASSI, E.; PÉLISSIER, R.; PLONTON, P.; 
RYAN, C. M.; SALDARRIAGA, J. G.; VIELLEDENT, G. Improved allometric models to estimate the aboveground biomass of tropical trees. Global Change Biology, v. 20, n. 10, p. 3177-3190, 2014. DOI: https://doi.org/10.1111/gcb.12629

CHAZDON, R. L.; ARROYO, J. P. Tropical forests as complex adaptive systems. In: MESSIER, C.; PUETTMANN, K. J.; COATES, K. D. (Eds). Managing Word forests as complex adaptatives systems in the face of global change. New York: Routlegde, 2013. pp 35-59.

COSTA, J. N. M. N. D.; DURIGAN, G. Leucaena leucocephala (Lam.) de Wit (Fabaceae): invasive or ruderal?. Revista Árvore, v. 34, n. 5, p. 825-833, 2010.

DE MELO, A. C. G.; MIRANDA, D. L. C.; DURIGAN, G. Cobertura de copas como indicador de desenvolvimento estrutural de reflorestamentos de restauração de matas ciliares no médio vale do Paranapanema, SP, Brasil. Revista Árvore, v. 31, n. 2, p. 321-328, 2017.

DEL RÍO, M.; PRETZSCH, H.; ALBERDI, I.; BIELAK, K.; BRAVOS, F.; BRUNNER, A.; CONDÉS, S.; DUCEY, M. J.; FONSECA, R.; Von LÜPKE, N.; PACH, M.; PERIC, S.; PEROT, T.; SOUIDI, Z.; SPATHELF, P.; STERBA, H.; TIJARDOVIC, M.; TOMÉ, M.; VALLET, P.; BRAVO-OVIEDO, A. Characterization of the structure, dynamics, and productivity of mixed-species stands: review and perspectives. European Journal of Forest Research, v. 135, n. 1, p. 23-49, 2016. DOI: https://doi.org/10.1007/s10342-015-0927-6

DOSSKEY, M. G.; VIDON, P.; GURWICK, N. P.; ALLAN, C. J.; DURVAL, T. P.; LOWRANCE, R. The role of riparian vegetation in protecting and improving chemical water quality in streams. Journal of the American Water Resources Association, v. 46, n. 2, p. 261-277, 2010. DOI: 10.1111/j.1752-1688.2010.00419.x

DURIGAN, G.; ENGEL, V. L. Restauração de ecossistemas no Brasil: onde estamos e para onde podemos ir? In: MARTINS, S. V. (Ed.). Restauração ecológica de ecossistemas degradados. Viçosa: Editora UFV, 2012. p. 41-68.

DURIGAN, G.; GUERIN, N.; COSTA, J. N. M. N. Ecological restoration of Xingu Basin headwaters: motivations, engagement, challenges and perspectives. Philosophical Transactions of the Royal Society B: Biological Sciences, v. 368, n. 1619, p. 1-9, 2013. DOI: 10.1098/rstb.2012.0165

ELLIOTT, S.; NAVAKITBUMRUNG, P.; KURAK, C.; ZANGKUM, S.; ANUSARNSUNTHORN, V.; BLAKESLEY, D. Selecting framework tree species for restoring seasonally dry tropical forests in northern Thailand based on field performance. Forest Ecology and Management, v. 184, n. 1-3, p. 177-191, 2013. DOI: https://doi.org/10.1016/S0378-1127(03)00211-1

ENGEL, V. L.; PARROTTA, J. A. An evaluation of direct seeding for reforestation of degraded lands in central Sao Paulo state, Brazil. Forest Ecology and Management, v. 152 , n. $1-3$, p. 169-181, 2001. DOI: http://dx.doi.org/10.1016/S0378-1127(00)00600-9

FREITAS, M. G.; RODRIGUES, S. B.; CAMPOS-FILHO, E. M.; CARMO, G. H. P.; VEIGA, J. M.; JUNQUEIRA, R. G. P.; VIEIRA, D. L. M. Evaluating the sucess of direct seeding for tropical Forest restoration over tem years. Forest Ecology and Magnagement, v. 438, p.
224-232,

2019.

DOI:

https://doi.org/10.1016/j.foreco.2019.02.024

GHAZOUL, J.; CHAZDON, R. Degradation and Recovery in Changing Forest Landscapes: A Multiscale Conceptual Framework. Annual Review of Environment and Resourses, v. 42, p. 161- 188, 2017. DOI: https://doi.org/10.1146/annurev-environ-102016060736

GIBBS, H. K.; SALMON, J. M. Mapping the world's degraded lands. Applied Geography, v. 57, n. 1, p. 2-21, 2015. https://doi.org/10.1016/j.apgeog.2014.11.024

GROSSNICKLE, S.; IVETIĆ, V. Direct seeding in reforestation - a field performance rewiew. Reforesta, v. 4, p. 94-142, 2017. DOI: https://orcid.org/0000-00030587-1422

GUARIGUATA， M. R.; BRANCALION， P. Current challenges and perspectives for governing forest restoration. Forests, v. 5, p. 3022-3030, 2014. DOI: https://doi.org/10.3390/f5123022

HENTTONEN, H. M.; NÖJD, P.; MÄKINEN, H. Environment-induced growth changes in the Finnish forests during 1971-2010 - an analysis based on National Forest Inventory. Forest Ecology and Management, v. 386, p. 22-36, 2017. DOI: 10.1016/j.foreco.2016.11.044

HOLL, K. D. Restoring Tropical Forest. Nature Education Knowledge, v. 4, n. 4, e4, 2013. Disponível em: https://www.nature.com/scitable/knowledge/library/r estoring-tropical-forest-97756726/

HOLL, K. D.; ZAHAWI, R. A. Factors explaining variability in wood above-ground biomass accumulation in restores tropical forest. Forest Ecology and Management, v. 319, p. 36-43, 2013. DOI: 10.1016/j.foreco.2014.01.024

HOUGHTON, R. A.; BYERS, B.; NASSIKAS, A. A. A role for tropical forests in stabilizing atmospheric $\mathrm{CO}_{2}$. Nature Climate Change, v. 5, n. 12, p. 1022-1023, 2015. DOI: https://doi.org/10.1038/nclimate2869

ISBELL, F.; COWLES, J.; DEE, L. E.; LOREAU, M.; REICH, P. B.; GONZALEZ, A.; HECTOR, A.; SCHMID, B. Quantifying effects of biodiversity on ecosystem functioning across times and places. Ecology Letters, v. 21, n. 6, p. 763-778, 2018. DOI: $10.1111 /$ ele. 12928

ISBELL, F.; GONZALEZ, A.; LOREAU, M.; COWLES, J.; DÍAZ, S.; HECTOR, A.; MACE, G. M.; WARDLE, D. A.; O'CONNOR, M. I.; DUFFY, E.; TURNBULL, L. A.; THOPSON, P. L.; LARIGAUDERIE, A. Linking the influence and dependence of people on biodiversity across scales. Nature, v. 546, e7656, p. 65-72, 2017. DOI: https://doi.org/10.1038/nature22899

LENTH, R.; LENTH, M. R. Package 'lsmeans'. The American Statistician, v. 34, n. 4, p. 216-221, 2018. DOI: 10.1080/00031305.1980.10483031

LUGO, A. E. The apparent paradox of reestablishing species richness on degraded lands with tree monocultures. Forest Ecology and Management, v. 99, p. 9-19, 1997.

MCDILL, M. E.; AMATEIS R. L. Measuring forest site quality using the parameters of a dimensionally compatible height growth function. Forest Science, v. 38 , n. 2, p. 409-429, 1992. DOI: https://doi.org/10.1093/forestscience/38.2.409

MITCHARD, E. T. A. The tropical forest carbon cycle and climate change. Nature, v. 559, e7715, p. 527-534, 2018. DOI: $10.1038 /$ s41586-018-0300-2 
MOREIRA, B.; TORMO, J.; PAUSAS, J. G. To resprout or not to resprout: factors driving intraspecific variability in resprouting. Oikos, v. 121, n. 10, p. 1577-1584, 2012. DOI: $10.1111 /$ j.1600-0706.2011.20258.x

MORI, A. S.; LERTZMAN, K. P.; GUSTAFSSON, L. Biodiversity and ecosystem services in Forest ecosystems: a research agenda for applied Forest ecology. Journal of Applied Ecology, v. 54, n. 1, p. 12-27, 2016. DOI: https://doi.org/10.1111/1365-2664.12669

NORONHA, J. C.; LIMA, M. M.; VELASQUEZ, C. L.; ALMEIDA, E. J.; BARROS, A. B.; RODRIGUES, D. J. Update das espécies de anuros da Fazenda São Nicolau, Mato Grosso, Brasil. Scientific Electronic Archives, v. 8 , n. 1, p. $15-25,2015$.

ONU_Organização das Nações Unidas. Declaração de Nova York sobre Florestas, USA. 2014. Disponível em: http:/ /www.greenbeltmovement.org/sites/greenbeltmo vement.org/files/Forests\%20Declaration\%20Text.pdf. Acessado em 12 mar. 2019.

PAKKAD, G.; TORRE, F.; ELLIO'T'T, S.; BLAKESLEY, D. Selecting seed trees for a forest restoration program: a case study using Spondias axillars Roxb. (Anacardiaceae). Forest Ecology and Management, v. 182, n. 1-3, p. 363-370, 2003. DOI: https://doi.org/10.1016/S03781127(03)00092-6

PALMA, A. C.; LAURANCE, S. G. A review of the use of direct seeding and seedling plantings in restoration: what do we know and where should we go?. Applied Vegetation Science, v. 18, n. 4, p. 561-568, 2015. DOI: $10.1111 /$ avsc. 12173

PAUSAS, J. G.; KEELEY, J. E. Evolutionary ecology of resprouting and seeding in fire-prone ecosystems. New Phytologist, v. 204, n. 1, p. 55-65, 2014. DOI: $10.1111 /$ nph. 12921

PAUSAS, J. G.; PRATT, R. B.; KEELEY, J. E.; JACOBSEN, A. L.; RAMIREZ, A. R.; VILAGROSA, A.; PAULA, S.; KANEAKUA-PIA, I. N.; DAVIS, S. D. Towards understanding resprouting at the global scale. New Phytologist, v. 209, n. 3, p. 945-954, 2016. DOI: 10.1111/nph.13644

PERRING, M. P.; STANDISH, R. J.; PRICE, J. N.; CRAIG, M. D.; ERICKSON, T. E.; RUTHOROF, K. X.; WHITELEY, A. S.; VALENTINE, L. E.; HOBBS, R. J. Advances in restoration ecology: rising to the challenges of the coming decades. Ecosphere, v. 6, n. 8, p. 1-25, 2015. DOI: https://doi.org/10.1890/ES15-00121.1

POORTER, L.; BONGERS, F.; AIDE, T. M.; ZAMBRANO, A. M. A.; BALVANERA, P.; BECKNELL, J. M.; BOUKILI, V.; BRACALION, P. H. S.; BROADBENT, E. N.; et al. Biomass resilience of Neotropical secondary forests. Nature, v. 530, e7589, p. 211, 2016. DO: Ihttps://doi.org/10.1038/nature16512

R CORE TEAM. R: A language and environment for statistical computing. R Foundation for Statistical Computing, Vienna, Áustria. 2018. Disponível em: https://www.R-project.org/. Acessado em 12 fev. 2019.

REIS, A.; BECHARRA, F. C.; TER, D. R. Nucleation in tropical ecological restoration. Scentia Agricola, v. 67, n. 2, p. 244-250, 2010.

RÉJOU-MÉCHAIN, M.; TANGUY, A.; PIPONIOT, C.; CHAVE, J.; HÉRAULT, B. Biomass: an r package for estimating above-ground biomass and its uncertainty in tropical forests. Methods in Ecology and Evolution, v.
8, n. 9, p. 1163-1167, 2017. DOI: https://doi.org/10.1111/2041-210X.12753

RODRIGUES, I. M. C.; SOUZA-FILHO, A. P. S.; FERREIRA, F. A.; DEMUNER, A. J. Prospecção química de compostos produzidos por Senna alata com atividade alelopática. Planta Daninha, v. 28, n. 1, p. 112, 2010. DOI: https://doi.org/10.1590/S010083582010000100001

RODRIGUES, R. R.; LIMA, R. A. F.; GANDOLFI, S.; NAVE, A. G. On the restoration of high diversity forests: 30 years of experience in the Brazilian Atlantic Forest. Biological conservation, v. 142, n. 6, p. 1242-1251, 2009. DOI: https://doi.org/10.1016/j.biocon.2008.12.008

SCOLFORO, J. R. S. Biometria florestal: modelos de crescimento e produção florestal. Lavras: Editora UFLA/FAEPE, 2006. 393p.

SILVA, J. A. A.; NOBRE, A. D.; JOLY, C. A.; NOBRE, C. A.; MANZATTO, C. V.; RECH-FILHO, E. L.; SKORUPA, L. A.; CUNHA, M. M. L. C.; MAY, P. H.; RODRIGUES, R. R.; AHRENS, S. The Brazilian Forest Code and Science: contributions to the dialogue. São Paulo: Sociedade Brasileira para o Progresso da Ciência - SBPC, 2012. 294p.

SILVEIRA, A. B.; SANTOS, J. P.; REBELLATO, L. Guia de boas práticas: Restauração e Áreas de Preservação Permanente Degradadas (APPD's). Experiência da Fazenda São Nicolau, Cotriguaçu, Mato Grosso. Cuiabá: PETRA, 2017. 76p. Disponível em: http://petra.eco.br/wp-

content/uploads/2017/10/guia_boaspraticas_web.pdf. Acesso em 28 fev. 2019.

SOARES-FILHO, B.; RAJÃO, R.; MACEDO, M.; CARNEIRO, A.; COSTA, W.; COE, M.; RODRIGUES, H.; ALENCAR, A. Crackin Brazil's Forest Code. Science, v. 344, e6182, p. 363-364, 2014. DOI: $10.1126 /$ science. 1246663

SOUZA, A. P.; MOTA, L. L.; ZAMADEI, T.; MARTIN, C. C.; ALMEIDA, F. T.; PAULINO, J. Classificação climática e balanço hídrico climatológico no estado de Mato Grosso. Nativa, v. 1, n. 1, p. 34-43, 2013. DOI: 10.31413/nativa.v1i1.1334

SOUZA, F. M.; DURIGAN, G. Enriquecimento de talhões puros de leucena com espécies nativas. In: DURIGAN, G.; RAMOS, V. S. Manejo Adaptativo: primeiras experiências na restauração de ecossistemas. São Paulo: Páginas \& Letras Editora e Gráfica, 2013. 49p.

SPRACKLEN, D. V.; BAKER, J. C. A.; GARCIACARRERAS, L.; MARSHAM, J. H. The effects of tropical vegetation on rainfall. Annual Review of Environment and Resources, v. 43, p. 193-218, 2018. DOI: https://doi.org/10.1146/annurev-environ102017-030136

TABACCHI, E.; LAMBS, L.; GUILLOY, H.; PANTYTABACCHI, A. M.; MULLER, E.; DÉCAMPS, H. Impacts of riparian vegetation on hydrological processes. Hydrological Processes, v. 14, n. 16-17, p. 2959-2976, $2000 . \quad$ DOI: $10.1002 / 1099$ 1085(200011/12)14:16/173.3.CO;2-2

TUCKER, N. I.; MURPHY, T. M. The effects of ecological rehabilitation on vegetation recruitment: some observations from the Wet Tropics of North Queensland. Forest Ecology and Management, v. 99, n. $1-2$, p. 133-152, 1997. DOI: https://doi.org/10.1016/S0378-1127(97)00200-4 
URIARTE, M.; CHAZDON, R. L. Incorporating natural regeneration in forest landscape restoration in tropical regions: synthesis and key research gaps. Biotropica, v. 48, n. 6, p. 915-924, 2016. DOI: https://doi.org/10.1111/btp.12411

VANCLAY, J. K. Modelling forest growth and yield: applications to mixed tropical forests. Oxford: Oxford University Press, School of Environmental Science and Management Papers, 1994. 537p.

VOURLITIS, G. L.; FILHO, N. P.; HAYASHI, M. M. S.; NOGUEIRA, J. D. S.; CASEIRO, F. T.; CAMPELO-JR, J. H. Seasonal variations in the evapotranspiration of a transitional tropical forest of Mato Grosso, Brazil. Water Resources Research, v. 38, n. 6, p. 1-11, 2002. DOI: https://doi.org/10.1029/2000WR000122

WATSON, J. E. M.; EVANS, T.; VENTER, O.; WILLIANS, B.; TULLOCH, A.; STEWART, C; THOPSON, I.; RAY, J. C.; MURRAY, K.; SALAZAR, A.; MCALPINE, C.; POTAV, P.; WALTSON, J.; ROBINSON, J. G.; PAINTER, M.; WILKIE, D.; FILARDI, C.; LAURANEC, W. F.; HOUGTON, R. A.; et al. The exceptional value of intact forest ecosystems. Nature Ecology \& Evolution, v. 2, n. 4, p. 599-610, 2018. DOI: https://doi.org/10.1038/s41559-018-0490-x

WRI Brasil. Surpresa na COP21: Estados Brasileiros se comprometem a restaurar mais de 3 milhões de hectares. 2019. Disponível em: http:// www.wribrasil.org.br/pt/blog/2016/01/surpresa-nacop21-estados-brasileiros-se-comprometem-restaurarmais-de-3- milh\%C3\%B5es-de. Acessado 10 mar. 2019.

ZEPPEL, M. J. B.; HARRISON, S. P.; ADAMS, H. D.; KELLEY, D. I.; LI, G.; TISSUE, D. T.; DAWSON, T. E.; FENSHAM, R.; MEDLYN, B. E.; PALMER, A.; WEST, A. G.; MCDOWELL, N. G. Drought and resprouting plants. New Phytologist, v. 206, n. 2, p. 583589, 2015. DOI: $10.1111 /$ nph.13205 